Article

\title{
Optimization of One-Step In Situ Transesterification Method for Accurate Quantification of EPA in Nannochloropsis gaditana
}

\author{
Yuting Tang ${ }^{1,2}$, Yue Zhang ${ }^{2}$, Julian N. Rosenberg ${ }^{2}$, Michael J. Betenbaugh ${ }^{2}$ and Fei Wang ${ }^{1, *}$ \\ 1 College of Chemical Engineering, Nanjing Forestry University, Jiangsu Key Lab of Biomass-based Green \\ Fuels and Chemicals, Nanjing 210037, China; amandatangvais@hotmail.com \\ 2 Department of Chemical \& Biomolecular Engineering, Johns Hopkins University, 3400 N. Charles St, \\ Baltimore, MD 21218, USA; yue_onlyone@hotmail.com (Y.Z.); jrosenberg@jhu.edu (J.N.R.); \\ beten@jhu.edu (M.J.B.) \\ * Correspondence: hgwf@njfu.edu.cn; Tel./Fax: +86-25-8542-7649
}

Academic Editor: Raed Abu-Reziq

Received: 27 September 2016; Accepted: 3 November 2016; Published: 8 November 2016

\begin{abstract}
Microalgae are a valuable source of lipid feedstocks for biodiesel and valuable omega-3 fatty acids. Nannochloropsis gaditana has emerged as a promising producer of eicosapentaenoic acid (EPA) due to its fast growth rate and high EPA content. In the present study, the fatty acid profile of Nannochloropsis gaditana was found to be naturally high in EPA and devoid of docosahexaenoic acid (DHA), thereby providing an opportunity to maximize the efficacy of EPA production. Using an optimized one-step in situ transesterification method (methanol:biomass $=90 \mathrm{~mL} / \mathrm{g} ; \mathrm{HCl} 5 \%$ by vol.; $70{ }^{\circ} \mathrm{C} ; 1.5 \mathrm{~h}$ ), the maximum fatty acid methyl ester (FAME) yield of Nannochloropsis gaditana cultivated under rich condition was quantified as $10.04 \% \pm 0.08 \%$ by weight with EPA-yields as high as $4.02 \% \pm 0.17 \%$ based on dry biomass. The total FAME and EPA yields were 1.58- and 1.23 -fold higher separately than that obtained using conventional two-step method (solvent system: methanol and chloroform). This one-step in situ method provides a fast and simple method to measure fatty acid methyl ester (FAME) yields and could serve as a promising method to generate eicosapentaenoic acid methyl ester from microalgae.
\end{abstract}

Keywords: EPA; FAME; one-step in situ transesterification; Nannochloropsis gaditana

\section{Introduction}

Microalgae represent a promising feedstock for biofuel and nutritional lipid production. Compared to land plants, algae can exhibit high biomass productivities and do not require high quality agricultural condition to grow, and thus do not directly compete with food crops for arable land [1]. In addition, these unicellular organisms can be harvested nearly year-round. Many species are even capable of robust growth in wastewater, thereby reducing freshwater usage [2]. In addition to fuels production, microalgae have historically been used to produce long-chain polyunsaturated fatty acids (PUFAs) [3]. In particular, PUFAs produced by microalgae have demonstrated their potential in the prevention and treatment of several diseases [4,5]. Eicosapentaenoic acid (EPA) and docosahexenoic acid (DHA) are two omega-3 PUFAs that have been shown to provide numerous cardiovascular benefits [5], making them popular health food ingredients. EPA must be obtained from external food sources such as fish, since it is poorly synthesized in the human body [6]. In addition to fish, EPA and DHA are also commercially available from microalgal sources [7]. Based on this success, efforts have been undertaken to evaluate alternative algal platforms as commercially feasible feedstocks for EPA and DHA at large scales. The estimated production cost for EPA and DHA supplements is 
approximately $39.1 \mathrm{USD} / \mathrm{kg}$ dry weight, when microalgae are phototrophically cultivated in flat panel reactors with high irradiance [8]. It potentially could be reduced to $11.9 \mathrm{USD} / \mathrm{kg}$ with advances in biological productivity and improvements in the engineering parameters [8].

Among the candidate microalgal organisms for omega-3 production, the Nannochloropsis genus has emerged as a promising source of EPA [3,9]. A number of factors affecting the biomass productivity and EPA content of Nannochloropsis spp. have been reported. Application of environmental stressors to trigger high biomass accumulation and impact lipid productivity have been successfully applied by using various nitrogen sources [10], controlling the concentration of nitrogen [11], manipulating the N:P supply ratio [12], and altering salinity, $\mathrm{pH}$ [13], and light intensity [14]. Furthermore, genetic tools and genomic information for a number of Nannochloropsis strains are currently under development [15].

The conventional two-step approach to algal fatty acid quantification suffers from compounding inefficiencies [16] and extraction yields that are highly dependent on the polarity of the solvents. A recent report demonstrated when polar solvent (chloroform/methanol (2:1), ethanol and acetone) was used for extraction, the lipid yield was much higher than by non-polar solvent (hexane) [17]. As a result, researchers have worked toward developing a one-step in situ transesterification method especially for algal biomass. In situ transesterification means the direct conversion of the lipids in algal biomass into fatty acid methyl esters using either acid or base catalysts, or other catalysts without lipid extraction procedure [18]. In addition, in situ methods provide more reliable and accurate data than gravimetric methods, in which the weight often includes non-saponifiable lipids and overestimates the extracts $[19,20]$. Related studies on biodiesel production from dried or wet microalgal biomass using in situ transesterification have been summarized by Chen et al. [21]. Unfortunately, much less attention has been paid to providing a simple, reliable, and rapid method to quantify the yield of omega-3 fatty acids from Nannochloropsis gaditana and other microalgae.

Therefore, in the present study, a novel one-step in situ transesterification procedure to quantify EPA and other fatty acids was examined in Nannochloropsis gaditana. Reaction parameters including methanol amount, concentration of acid catalyst, reaction time, and temperature were optimized in batch reaction mode. This optimized in situ method could serve as a promising method to generate eicosapentaenoic acid methyl ester. Furthermore, the EPA and fatty acid methyl ester (FAME) yields of the in situ procedure and the two-step method were compared.

\section{Materials and Methods}

\subsection{Reagents}

Nannochloropsis strain number Chl-2 was purchased from IOCAS (Institute of Oceanology, Chinese Academy of Sciences, Qingdao, China) and identified as N. gaditana by the colony PCR and phylogenetic analysis methods of Rosenberg et al. [22]. Analytical grade organic solvents including chloroform, methanol, petroleum ether, ethyl ether, and hydrochloric acid were purchased from Sunshine Inc., Nanjing, China. Methyl palmitoleate (16:1, $\geq 99 \%$ purity) and methyl heptadecanoate (17:0, $\geq 99 \%$ purity) were purchased from Sigma Aldrich, Shanghai, China. Methyl palmitate (16:0) and methyl all-cis-5, 8,11,14,17-eicosapentaenoate (20:5) were purchased from Fluka, Shanghai, China.

\subsection{Cultivation Conditions}

Nannochloropsis gaditana was cultured in BG-11 medium containing the following components: $1.5 \mathrm{~g} \cdot \mathrm{L}^{-1} \mathrm{NaNO}_{3}, 40 \mathrm{mg} \cdot \mathrm{L}^{-1} \mathrm{KH}_{2} \mathrm{PO}_{4} \cdot 3 \mathrm{H}_{2} \mathrm{O}, 75 \mathrm{mg} \cdot \mathrm{L}^{-1} \mathrm{MgSO}_{4} \cdot 7 \mathrm{H}_{2} \mathrm{O}, 36 \mathrm{mg} \cdot \mathrm{L}^{-1} \mathrm{CaCl}_{2} \cdot 2 \mathrm{H}_{2} \mathrm{O}$, $6.0 \mathrm{mg} \cdot \mathrm{L}^{-1}$ citric acid, $6.0 \mathrm{mg} \cdot \mathrm{L}^{-1}$ ferric ammonium citrate, $1.0 \mathrm{mg} \cdot \mathrm{L}^{-1} \mathrm{EDTA}, 20 \mathrm{mg} \cdot \mathrm{L}^{-1} \mathrm{Na}_{2} \mathrm{CO}_{3}$, and $1.0 \mathrm{~mL} \cdot \mathrm{L}^{-1} \mathrm{~A}^{5+} \mathrm{Co}^{*}$ solution. The $\mathrm{A}^{5+} \mathrm{Co}^{*}$ solution contained $2.86 \mathrm{~g} \cdot \mathrm{L}^{-1} \mathrm{H}_{3} \mathrm{BO}_{3}, 1.81 \mathrm{~g} \cdot \mathrm{L}^{-1}$ $\mathrm{MnCl}_{2} \cdot \mathrm{H}_{2} \mathrm{O}, 222 \mathrm{mg} \cdot \mathrm{L}^{-1} \mathrm{ZnSO}_{4} \cdot 7 \mathrm{H}_{2} \mathrm{O}, 79 \mathrm{mg} \cdot \mathrm{L}^{-1} \mathrm{CuSO}_{4} \cdot 5 \mathrm{H}_{2} \mathrm{O}, 390 \mathrm{mg} \cdot \mathrm{L}^{-1} \mathrm{Na}_{2} \mathrm{MoO}_{4} \cdot 2 \mathrm{H}_{2} \mathrm{O}$, and $49 \mathrm{mg} \cdot \mathrm{L}^{-1} \mathrm{Co}\left(\mathrm{NO}_{3}\right)_{2} \cdot 6 \mathrm{H}_{2} \mathrm{O}$ [23]. Small-scale growth experiments were carried out in 1-L batch cultures to obtain growth curve data. When cultures ultimately entered stationary phase, cultures were diluted $50 \%$ using fresh medium to obtain a semi-continuous cultivation period of seven days. 
Other culture conditions included white fluorescent illumination at $50 \mu \mathrm{E} \cdot \mathrm{m}^{-2} \cdot \mathrm{s}^{-1}$ with $12 / 12 \mathrm{~h}$ light/dark photoperiod, at $25^{\circ} \mathrm{C}$ throughout the experiment.

\subsection{One-Step In Situ Transesterification}

Microalgal biomass was harvested by centrifugation at stationary phase and immediately lyophilized for $24 \mathrm{~h}$ at $-40{ }^{\circ} \mathrm{C}$ under vacuum. The one-step in situ transesterification reaction was carried out in a glass reactor with stirring in the presence of $500 \mu \mathrm{g}$ methyl heptadecanoate (17:0) as an internal standard. A prescribed amount of biomass, methanol and $\mathrm{HCl}$ was placed in the reactor and was heated to the preset temperature. After the reaction, the resulting FAME fraction was extracted by hexane and quantified by gas chromatography (GC) after neutralization. The procedure was duplicated under different reaction conditions with Methanol/biomass $(\mathrm{mL} / \mathrm{g})$ from 30 to 120; $\mathrm{HCl} / \mathrm{MeOH}$ from 2.5 to 11 ; reaction temperature from 60 to $90{ }^{\circ} \mathrm{C}$; and reaction time from $0.5-2.5 \mathrm{~h}$. The procedure adopted here has been previously described in literature [19].

\subsection{Quantitative Analysis}

The FAME yields were analyzed by GC (Agilent $6890 \mathrm{~N}$, Aligent, Beijing, China) with flame ionization detection equipped with a capillary column (Agilent HP-5, $30 \mathrm{~m} \times 0.25 \mathrm{~mm}$ ID, film thickness $0.25 \mu \mathrm{m}$, Aligent, Beijing, China). The injector and detector temperature of GC was set at $250{ }^{\circ} \mathrm{C}$. The temperature program was started at $80{ }^{\circ} \mathrm{C}$ and then increased to $175{ }^{\circ} \mathrm{C}$ at a rate of $20{ }^{\circ} \mathrm{C} \cdot \mathrm{min}^{-1}$, plateauing for $1 \mathrm{~min}$. The rate was decreased to $4{ }^{\circ} \mathrm{C} \cdot \mathrm{min}^{-1}$ from 175 to $235{ }^{\circ} \mathrm{C}$ and kept constant remained for $9 \mathrm{~min}$. Helium was used as the constant carrier gas. Qualitative analysis of the major FAME (methyl palmitoleate (16:1), methyl palmitate (16:0), methyl all-cis-5,8,11,14,17-eicosapentaenoate (20:5) was based on individual FAME peaks and quantitative study of the major FAME was using a five-point calibration curve $\left(0.5-2.5 \mathrm{mg} \cdot \mathrm{mL}^{-1}\right)$ obtained by a series of FAME standards with methyl heptadecanoate (17:0) as internal standard.

\subsection{Two-Step Method for Lipid Extraction and Transesterification}

For lipid extraction using a modified Bligh and Dyer method [24], $100 \mathrm{mg}$ of the lyophilized biomass was blended with $3.75 \mathrm{~mL}$ solvent mixture (chloroform:methanol:distilled water $=1: 2: 0.75$, $v / v / v$ ) in a flask. The mixture was homogenized with a magnetic stirrer at $300 \mathrm{rpm}$ for $1 \mathrm{~h}$. Then $1 \mathrm{~mL}$ chloroform and $0.5 \mathrm{~mL}$ of distilled water were added into the mixed solvent to form two layers. After 10 min centrifugation at $1500 \times g$, the upper layer containing the mixture of methanol and distilled water was gently removed by a Pasteur pipette. The lower layer containing chloroform was collected and then filtered with a fiber filter of $0.45 \mu \mathrm{m}$. The sediment was re-extracted as the former steps and the residue was light colored. After evaporating the filtered solvent by a rota-evaporator, the lipids were obtained gravimetrically. Similar lipid extraction was performed using petroleum ether and ethyl ether in which $100 \mathrm{mg}$ of the lyophilized biomass was blended with $6 \mathrm{~mL}$ solvent mixture (petroleum ether: ethyl ether $=2: 1, v / v$ ) in a $25 \mathrm{~mL}$ flask. Extraction was performed at $40{ }^{\circ} \mathrm{C}$ for $4 \mathrm{~h}$ with a condensing device. After filtering and evaporation, the lipids were obtained gravimetrically. In both cases, transesterification of the weighed lipids were accomplished with $9 \mathrm{~mL} \mathrm{MeOH}$ with $\mathrm{HCl}$ $5 \%$ by vol., at $70{ }^{\circ} \mathrm{C}$ for $1.5 \mathrm{~h}$ with $1500 \mu \mathrm{g}$ methyl heptadecanoate as the internal standard. The process was in duplicated.

\section{Results}

\subsection{Analysis of FAME Profiles and Contents}

The FAME profiles and contents of the in situ procedure were analyzed by GC and the reaction conditions of the in situ method were: methanol:biomass $=90 \mathrm{~mL} / \mathrm{g}, \mathrm{HCl} 5 \%$ by vol., $70{ }^{\circ} \mathrm{C}, 1.5 \mathrm{~h}$. As shown in Table 1, the relative FAME profiles of Nannochloropsis gaditana resolved by GC consist of methyl myristate (14:0), methyl palmitoleate (16:1), methyl palmitate (16:0), methyl cis-9-octadecenoate 
(18:1), methyl cis,cis-9,12-octadecadienoate (18:2), and methyl all-cis-5,8,11,14,17-eicosapentaenoate (20:5). Other peaks were observed but not resolved and may include alkanes and alkyl diols according to mass spectra. Fatty alcohols and alkyl diols are known in Nannochloropsis oculata from other reports as well [25].

Table 1. Composition of fatty acid methyl ester (FAME) produced from Nannochloropsis gaditana using the $\mathrm{HCl}$-catalyzed in situ procedure. The reaction conditions of the in situ method were: methanol:biomass $=90 \mathrm{~mL} / \mathrm{g}, \mathrm{HCl} 5 \%$ by vol., $70{ }^{\circ} \mathrm{C}, 1.5 \mathrm{~h}$. Each value \% (of the total peak area) is the average of two independent experiments with duplicates.

\begin{tabular}{cc}
\hline Type of FAME & Amount (Peak Area \%) \\
\hline $14: 0$ & $3.11 \pm 0.06$ \\
$16: 1$ & $18.34 \pm 0.17$ \\
$16: 0$ & $26.60 \pm 0.20$ \\
$18: 0$ & $6.78 \pm 0.04$ \\
$18: 1 \& 18: 2$ & $8.95 \pm 0.04$ \\
$20: 5$ & $34.46 \pm 0.43$ \\
Others & $1.75 \pm 0.03$ \\
\hline
\end{tabular}

Nannochloropsis gaditana contained as much as $34.46 \%$ of its total fatty acids as EPA, which represented the most abundant FAME measured by in situ transesterfication. Other FAME components in large amounts include methyl palmitate $(16: 0,26.60 \%)$ and methyl palmitoleate $(16: 1,18.34 \%)$. Other FAME was detected in small quantity. The fatty acid profile of Nannochloropsis gaditana was observed to be naturally high in EPA and devoid of DHA, thereby providing an opportunity to maximize the efficacy of EPA quantification with this method.

\subsection{Optimization of In Situ Transesterification Reaction}

\subsubsection{Effect of Methanol-to-Biomass Ratio on Reaction Efficiency}

In order to optimize the in situ transesterification reaction, ratios of methanol-to-biomass between $30-120 \mathrm{~mL} \cdot \mathrm{g}^{-1}$ were evaluated. The effect of methanol-to-biomass ratio on reaction efficiency is shown in Figure 1. Ratios lower than $30 \mathrm{~mL} \cdot \mathrm{g}^{-1}$ were not examined due to biomass wetting limitations. At a low methanol-to-biomass ratio of $30 \mathrm{~mL} \cdot \mathrm{g}^{-1}$, the major FAMEs only accounted for $7.41 \% \pm 0.08 \%$ of the total biomass. For complete conversion of lipid into FAME, excess methanol was needed since transesterification is a reversible reaction. Therefore, excess methanol contributes to the reaction favoring the formation of glycerol and FAME while reaching equilibrium within a reasonable time. Additionally, the high viscosity of microalgal lipids has a detrimental effect on the interaction of lipids and methanol. The slow contact of lipid and methanol resulted in inefficient mass transfer along with unfavorable FAME conversions. As the methanol-to-biomass ratio increased to $90 \mathrm{~mL} \cdot \mathrm{g}^{-1}$, higher total FAME yields were attained $(10.04 \% \pm 0.14 \%)$ and the EPA yield reached its highest level $\left(4.02 \% \pm 0.17 \%\right.$ of total biomass). When the methanol-to-biomass ratio was increased to $120 \mathrm{~mL} \cdot \mathrm{g}^{-1}$, FAME yield decreased to roughly $9.27 \% \pm 0.02 \%$, which suggests that some protein and carbohydrate components of the biomass may have been co-extracted in the excess methanol [26]. In addition, the free fatty acid (FFA) and triacylglycerol (TAG) in microalgae can both be converted to FAME and less methanol is required for FFA dissolution and conversion than TAG. Thus, $90 \mathrm{~mL} \cdot \mathrm{g}^{-1}$ was found to be the optimal methanol-to-biomass ratio and was employed for the following experiments. 


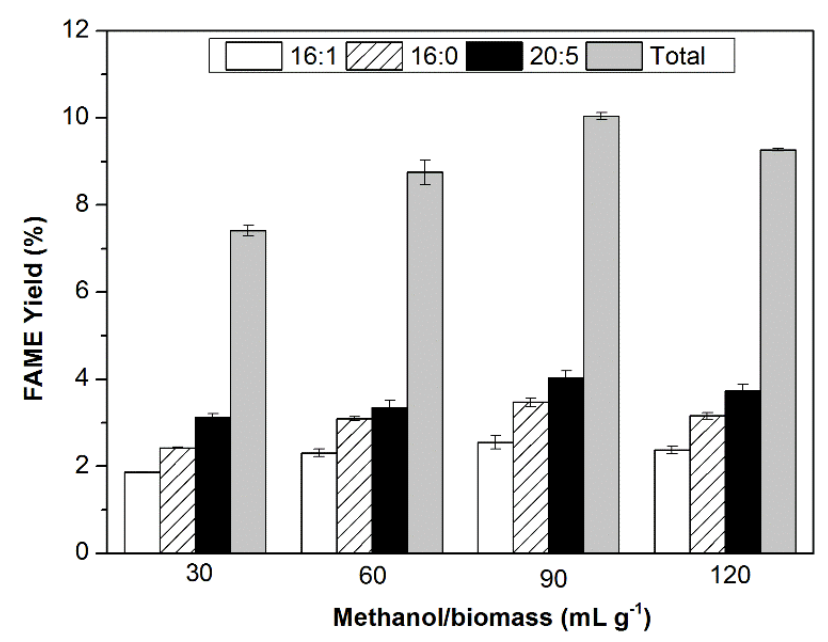

Figure 1. Effect of the ratio between methanol and biomass on the fatty acid methyl ester (FAME) yield. Reaction conditions: $\mathrm{HCl} / \mathrm{Methanol}(5 \%, v / v)$, reaction temperature: $70^{\circ} \mathrm{C}$, reaction time: $1.5 \mathrm{~h}$.

\subsubsection{Effect of Acid Concentration on Reaction Efficiency}

Acid catalysts are widely used for transesterification due to their ability to catalyze all free or linked fatty acids. Base catalysts have prominent advantages compared to acid catalysts, the reaction time is shorter and the requirement for the equipment for the reaction is not as high as that of acid catalysts in case of corrosion. However, base catalysis has high selectivity based on the type of lipids. Base catalysis methods showed lower FAME yield compared to the yield obtained by acid catalysis [19]. The base catalysts may not be able to penetrate through the thick algal cell wall and the existing free fatty acid may be subjected to saponification in base catalyzed transesterification. Therefore, acid catalysis was chosen in our study and the effect of acid concentration on the in situ transesterification is shown in Figure 2. As the concentration of acid catalyst increased, the FAME content was also enhanced. When the acid concentration was $2.5 \%$, FAME yield was extremely low at $8.01 \% \pm 0.05 \%$. As the acid concentration increased to $5 \%$, the FAME yield increased to $10.04 \% \pm 0.08 \%$. However, upon further increase of the acid concentration from $5 \%$ to $11 \%$, no obvious improvement in the FAME yield was observed. Considering the cost and the corrosive characteristic of acid to the equipment, a catalyst concentration of $5 \%$ was chosen as the optimum value.

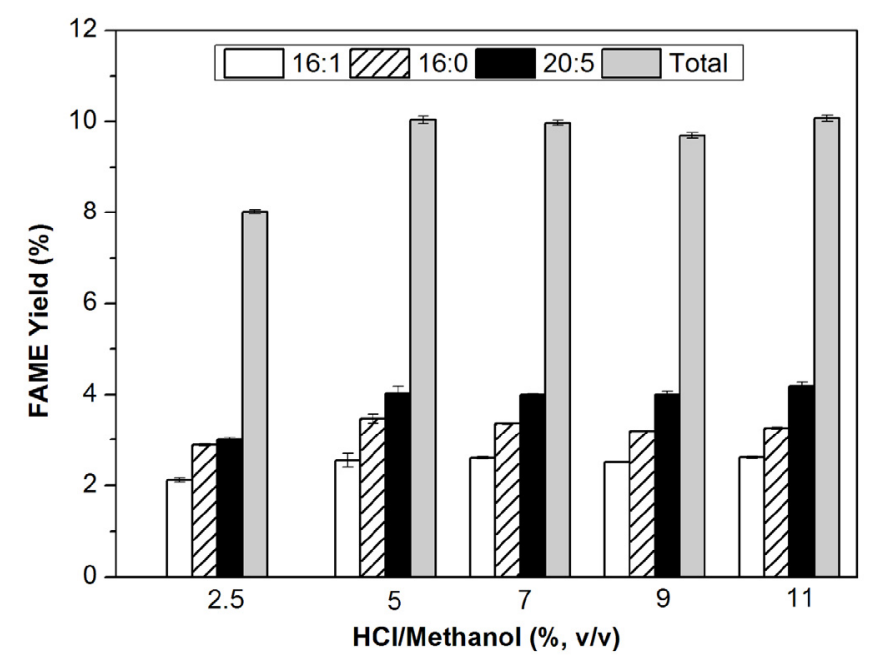

Figure 2. Effect of acid concentration on the FAME yield. Reaction conditions: methanol-to-biomass ratio: $90 \mathrm{~mL} \cdot \mathrm{g}^{-1}$, reaction temperature: $70{ }^{\circ} \mathrm{C}$, reaction time: $1.5 \mathrm{~h}$. 


\subsubsection{Effect of Reaction Time on Reaction Efficiency}

The FAME yields achieved by adopting different reaction times are shown in Figure 3. The FAME yield was $6.53 \% \pm 0.05 \%$ at $0.5 \mathrm{~h}$, and the conversion increased substantially to $10.04 \% \pm 0.08 \%$ at $1.5 \mathrm{~h}$. Further prolonged reaction time from 1.5 to $2.5 \mathrm{~h}$ did not increase the FAME yield. The reaction progressed forward due to the large amount of lipids and methanol and small amount of triglyceride and FAME initially. FAME content did not increase with longer reaction times since the reaction had reached equilibrium. Thus the equilibrium conversion of lipids to FAME could be completed after $1.5 \mathrm{~h}$ and this was chosen as the optimal reaction time.

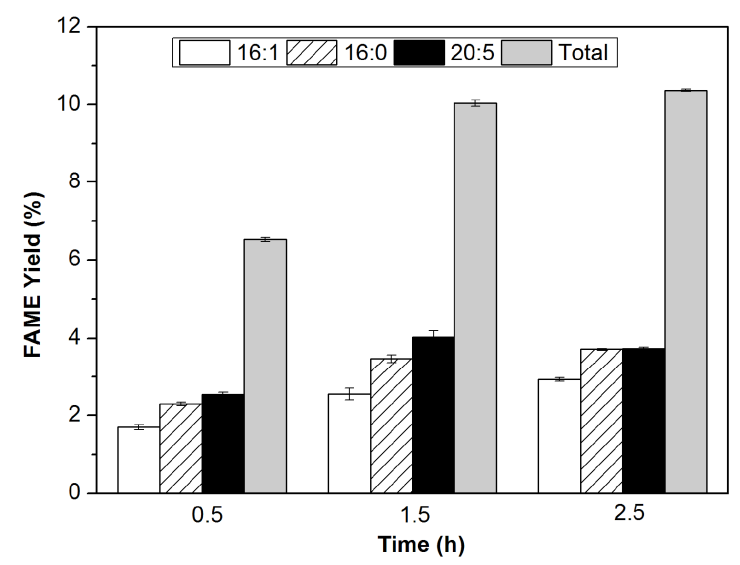

Figure 3. Effect of reaction time on the FAME yield. Reaction conditions: methanol-to-biomass ratio: $90 \mathrm{~mL} \cdot \mathrm{g}^{-1}, \mathrm{HCl} /$ Methanol $(5 \%, v / v)$, reaction temperature: $70{ }^{\circ} \mathrm{C}$.

\subsubsection{Effect of Reaction Temperature on Reaction Efficiency}

The reaction temperature exhibited notable effects on the efficiency of transesterification. FAME yields under 60, 70, 80, and $90^{\circ} \mathrm{C}$ are summarized in Figure 4. Temperatures higher than $90{ }^{\circ} \mathrm{C}$ were not studied because these higher temperatures may be impractical. The FAME yield was $9.6 \%$ at a reaction temperature of $60^{\circ} \mathrm{C}$. When the reaction temperature was progressively increased to $70{ }^{\circ} \mathrm{C}$, a higher FAME yield of $10.04 \% \pm 0.08 \%$ could be achieved. The high temperature may contribute to the disruption of the cell wall to ensure the reaction happens thoroughly. When the temperature was further raised to $90{ }^{\circ} \mathrm{C}$, the FAME yield dropped to $9.41 \% \pm 0.02 \%$. Methanol will evaporate under high temperatures and less reactant will have a detrimental effect on the production of FAME. Hence, a reaction temperature of $70^{\circ} \mathrm{C}$ was chosen as the optimum value in this study.

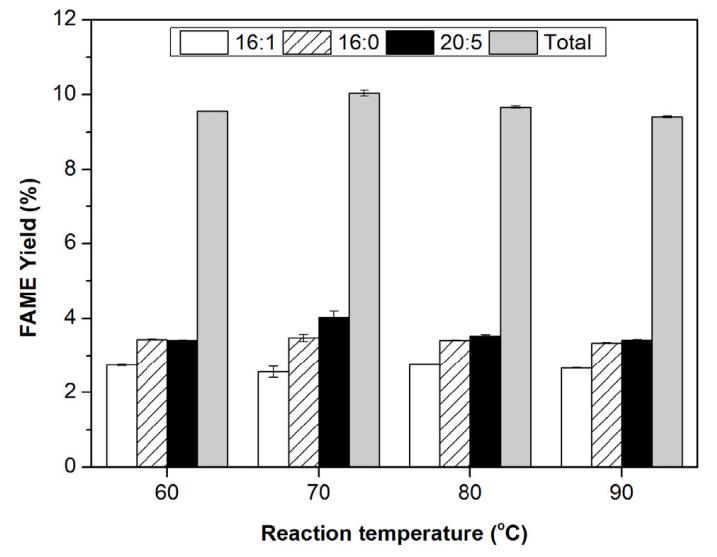

Figure 4. Effect of reaction temperature on the FAME yield. Reaction conditions: methanol-to-biomass ratio: $90 \mathrm{~mL} \cdot \mathrm{g}^{-1}, \mathrm{HCl} /$ Methanol $(5 \%, v / v)$, reaction time: $1.5 \mathrm{~h}$. 


\subsubsection{Effect of Extraction Solvent on Gravimetric Lipid Content and Total Fatty Acid Yields}

A relationship between the gravimetric yield and main FAME components of total extract is shown in Figure 5a. The gravimetric yield of crude extract using mixed methanol and chloroform was $26.40 \% \pm 0.34 \%$, while it was only $12.90 \% \pm 0.23 \%$ when adopting petroleum ether and ethyl ether. This phenomenon is likely due to the propensity of polar solvents to penetrate the cell wall more easily than non-polar solvents. The total FAME content as a percent of total extracted materials in methanol and chloroform extraction was $24.11 \% \pm 0.53 \%$ and in petroleum ether and ethyl ether extraction was only $12.93 \% \pm 0.02 \%$, suggesting that methanol and chloroform extraction could obtain more FAME than petroleum ether and ethyl ether extraction. However, the total extract clearly contains a large amount of other lipids and biomolecules soluble in the solvents in addition to FAME.

We also compared one-step in situ transesterification with the conventional two-step method that involves solvent extraction followed by acid transesterification after measuring the gravimetrical weight of the crude lipids. From Figure $5 b$, it could be also found that the EPA and other main FAME yields from the two-step method were lower than that for in situ transesterification, indicating that direct in situ transesterification allows for a more complete measurement of FAME as opposed to the two-step method. In the two-step method, the differential EPA yields were $3.26 \% \pm 0.10 \%$ using methanol and chloroform as the extraction solvent and $0.78 \% \pm 0.01 \%$ using petroleum ether and ethyl ether. These values are low compared to the in situ yield of $4.02 \% \pm 0.17 \%$ EPA presumably due to the following reasons: the lipids which do not convert into FAME account for a significant percentage of extracted crude oil; there are unavoidable losses of sample during the procedures and the lipids cannot be completely extracted by this method. The effectiveness of petroleum ether and ethyl ether on the extract-basis is quite low.

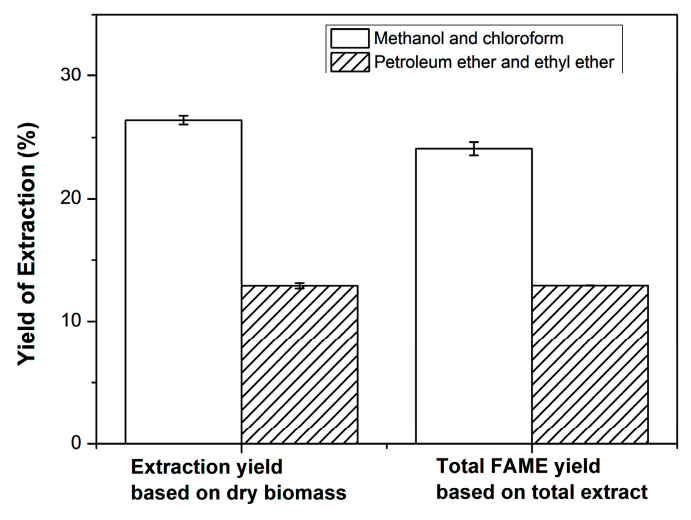

(a)

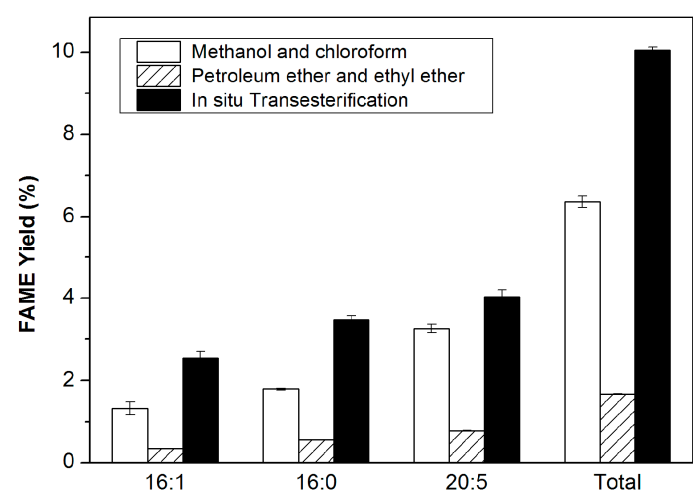

(b)

Figure 5. (a) Extraction yield based on dry biomass; FAME yield based on total extract (\%DW); (b) FAME yield of dry biomass (\%DW).

\section{Discussion}

The lipid fractions of algal biomass can differ significantly between species and vary under different growth conditions [27]. Furthermore, microalgae produce a variety of other lipophilic biomolecules such as pigments, waxes, proteins, and sterols. In order for lipid extraction and quantification methods to be accurate, procedures must effectively discern fatty acids from other lipid-soluble compounds, which cannot be converted to FAME. Oftentimes, lipophilic components of the biomass are co-extracted during the extraction process and can potentially overestimate the lipid yield. In particular, the polarity of solvents has a large effect on the lipid extraction yields using the conventional two-step approach. Relative to the conventional two-step method of lipid extraction and transesterification, one-step in situ transesterification offers a reliable and accurate method to measure FAME yields. Only small quantities of microalgal biomass are required for one-step in 
situ transesterification, which provides a fast and simple method for the selection of microalgae by calculating FAME content.

In the present study, the gravimetric yields of crude lipid extracts using methanol and chloroform were generally higher than the petroleum ether and ethyl ether solvent system with corresponding FAME yields of $24.11 \%$ and $12.93 \%$, respectively. Indeed, algal lipid yields typically increase with the polarity of the solvent, which is in accordance with the literature [28]. Since total lipid yields were higher in methanol and chloroform, this polar solvent system likely co-extracted carbohydrates, protein, salts, and other polar impurities. Polar solvents can extract different lipids classes, as well as carotene, sterols, etc. [29]. Carbohydrates and proteins can account for a significant portion of microalgal biomass-as high as $24 \%-33 \%$ carbohydrates and $36 \%-44 \%$ protein in Nannochloropsis gaditana [30], $28 \%$ starch, and $35 \%$ proteins in Dunaliella salina [31].

Fatty acids are an important class of lipids with commercially viable applications using triacylglycerols as biofuels and polyunsaturated fatty acids as nutrition oils. Currently, the principal source of PUFAs is fish. However, the high demand for consumption of PUFAs is likely to not be met by fish alone. In addition, the consumption of fish oil has a number of limitations due to the potential danger of contamination and fish odor [32,33]. Microalgae, such as Phaeodactylum, Thalassiosira, and Nannochloropsis species could serve as alternative sources of valuable EPA [3,7]. Developments in cost-effective and large-scale production of microalgae would make this process more sustainable [34].

For isolating EPA from Nannochloropsis gaditana, numerous previous studies have focused on the conventional two-step extraction method. Mitra et al. used this conventional method to obtain FAME from Nannochloropsis gaditana and observed that the EPA content was between $19.1 \%$ and $37.8 \%$ of the total fatty acids depending on the salinity [35]. Kim et al. stated that the FAME yield under normal white light was $11.4 \%$ of dry biomass using the conventional two-step method, and the maximal EPA content was 20.3\% of the total FAME from Nannochloropsis gaditana [36]. In the current study, the novel in situ transesterification method was optimized based on a variety of parameters. Compared to the conventional method, larger amounts of EPA were obtained in the lipid extract using this optimized method, which also demonstrates that this strain of Nannochloropsis gaditana is a promising source of EPA. The fast and simple one-step method may indeed reduce the chances of EPA being oxidized, since EPA is air and light sensitive. Given the high content of EPA in the lipid fraction, Nannochlorpsis gaditana is more suitable for producing polyunsaturated fatty acids than biofuels, since PUFAs are not suitable to be used as biodiesel due to their negative effects on oxidative stability and cold flow properties. In addition, the cetane number of oil abundant in PUFAs may not meet the standard for usage of biodiesel.

Compared to the conventional two-step method of lipid extraction and quantification, higher total FAME and lipid yields were achieved in the one-step in situ procedure. Thus, the one-step in situ method examined in the current study has the potential to be widely used for rapid quantitative assessment of microalgae as feedstocks for lipids and platforms for algal biology research. While the one-step in situ method investigated in the present study proved to be rapid method of measuring all FAME lipids relevant to biofuel and nutritional markets, Kobayashi et al. also reported a rapid method to characterize and quantify lipids by high performance liquid chromatography-evaporative light scattering detector (HPLC-ELSD) [37]. The major lipid classes such as carotenoids, TAG, diacylglycerol (DAG), free fatty acids, phospholipids, and galactolipids can be discerned by HPLC-ELSD, which may serve as a complementary method of lipid characterization. Nonetheless, in situ transesterification reduces the process time and volume of solvent required, which in turn reduces the impact on the environment.

\section{Conclusions}

Our experimental data indicate that one-step in situ transesterification is capable of extracting a higher amount of EPA, reaching up to $34.46 \%$ of the total FAME and $4.02 \%$ of the total dry biomass under optimal conditions. The one-step transesterification method provides a fast, simple, and reliable 
method to measure FAME yields that can provide greater accuracy for quantitative assessments in the future. Given the high content of EPA found in Nannochloropsis gaditana, this strain is as applied as a biofuel or nutritional supplement among other applications and this optimized method shows considerable promise for the recovery of omega-3 fatty acids from other microalgal species.

Acknowledgments: The authors gratefully acknowledge the financial support from the Natural Science Foundation of Jiangsu Universities (11KJA480001) and the National Natural Science Foundation of China (31170537). Partial support was also provided by grant number NSF-EFRI-1332344 from the National Science Foundation (MJB), DOE DE-SC0012658 grant (MJB) and a fellowship to JNR from the Johns Hopkins Environment, Energy, Sustainability \& Health Institute (E2SHI). This work was also supported by the Priority Academic Program Development of Jiangsu Higher Education Institutions (PAPD).

Author Contributions: Yuting Tang and Yue Zhang conceived and designed the experiments; Yuting Tang performed the experiments; Yuting Tang, Yue Zhang and Julian N. Rosenberg analyzed the data; Michael J. Betenbaugh and Fei Wang contributed reagents/materials/analysis tools; all the authors participated to the writing of the paper.

Conflicts of Interest: The authors declare no conflict of interest.

\section{References}

1. Ahmad, A.L.; Yasin, N.H.M.; Derek, C.J.C.; Lim, J.K. Microalgae as a sustainable energy source for biodiesel production: A review. Renew. Sustain. Energy Rev. 2011, 15, 584-593. [CrossRef]

2. Pires, J.C.M.; Alvim-Ferraz, M.C.M.; Martins, F.G.; Simões, M. Wastewater treatment to enhance the economic viability of microalgae culture. Environ. Sci. Pollut. Res. 2013, 20, 5096-5105. [CrossRef] [PubMed]

3. Ryckebosch, E.; Bruneel, C.; Termote-Verhalle, R.; Goiris, K.; Muylaert, K.; Foubert, I. Nutritional evaluation of microalgae oils rich in omega-3 long chain polyunsaturated fatty acids as an alternative for fish oil. Food Chem. 2014, 160, 393-400. [CrossRef] [PubMed]

4. Mozaffarian, D.; Wu, J.H.Y. Omega-3 fatty acids and cardiovascular disease: Effects on risk factors, molecular pathways, and clinical events. J. Am. Coll. Cardiol. 2011, 58, 2047-2067. [CrossRef] [PubMed]

5. Ruxton, C.H.S.; Calder, P.C.; Reed, S.C.; Simpson, M.J.A. The impact of long-chain n-3 polyunsaturated fatty acids on human health. Nutr. Res. Rev. 2005, 18, 113-129. [CrossRef] [PubMed]

6. Burdge, G.C.; Calder, P.C. Conversion of $\alpha$-linolenic acid to longer-chain polyunsaturated fatty acids in human adults. Reprod. Nutr. Dev. 2005, 45, 581-597. [CrossRef] [PubMed]

7. Collins, M.L.; Lynch, B.; Barfield, W.; Bull, A.; Ryan, A.S.; Astwood, J.D. Genetic and acute toxicological evaluation of an algal oil containing eicosapentaenoic acid (epa) and palmitoleic acid. Food Chem. Toxicol. 2014, 72, 162-168. [CrossRef] [PubMed]

8. Chauton, M.S.; Reitan, K.I.; Norsker, N.H.; Tveterås, R.; Kleivdal, H.T. A techno-economic analysis of industrial production of marine microalgae as a source of epa and dha-rich raw material for aquafeed: Research challenges and possibilities. Aquaculture 2015, 436, 95-103. [CrossRef]

9. Ma, Y.; Wang, Z.; Yu, C.; Yin, Y.; Zhou, G. Evaluation of the potential of 9 nannochloropsis strains for biodiesel production. Bioresour. Technol. 2014, 167, 503-509. [CrossRef] [PubMed]

10. Campos, H.; Boeing, W.J.; Dungan, B.N.; Schaub, T. Cultivating the marine microalga nannochloropsis salina under various nitrogen sources: Effect on biovolume yields, lipid content and composition, and invasive organisms. Biomass Bioenergy 2014, 66, 301-307. [CrossRef]

11. Wan, C.; Bai, F.-W.; Zhao, X.-Q. Effects of nitrogen concentration and media replacement on cell growth and lipid production of oleaginous marine microalga nannochloropsis oceanica dut01. Biochem. Eng. J. 2013, 78, 32-38. [CrossRef]

12. Mayers, J.J.; Flynn, K.J.; Shields, R.J. Influence of the n:P supply ratio on biomass productivity and time-resolved changes in elemental and bulk biochemical composition of nannochloropsis sp. Bioresour. Technol. 2014, 169, 588-595. [CrossRef] [PubMed]

13. Khatoon, H.; Abdu Rahman, N.; Banerjee, S.; Harun, N.; Suleiman, S.S.; Zakaria, N.H.; Lananan, F.; Abdul Hamid, S.H.; Endut, A. Effects of different salinities and ph on the growth and proximate composition of nannochloropsis sp. And tetraselmis sp. Isolated from south china sea cultured under control and natural condition. Int. Biodeterior. Biodegrad. 2014, 95 Part A, 11-18. [CrossRef] 
14. Simionato, D.; Sforza, E.; Corteggiani Carpinelli, E.; Bertucco, A.; Giacometti, G.M.; Morosinotto, T. Acclimation of nannochloropsis gaditana to different illumination regimes: Effects on lipids accumulation. Bioresour. Technol. 2011, 102, 6026-6032. [CrossRef] [PubMed]

15. Wang, D.; Ning, K.; Li, J.; Hu, J.; Han, D.; Wang, H.; Zeng, X.; Jing, X.; Zhou, Q.; Su, X.; et al. Nannochloropsis genomes reveal evolution of microalgal oleaginous traits. PLoS Genet. 2014, 10, e1004094. [CrossRef] [PubMed]

16. Mercer, P.; Armenta, R.E. Developments in oil extraction from microalgae. Eur. J. Lipid Sci. Technol. 2011, 113, 539-547. [CrossRef]

17. McNichol, J.; MacDougall, K.; Melanson, J.; McGinn, P. Suitability of soxhlet extraction to quantify microalgal fatty acids as determined by comparison with in situ transesterification. Lipids 2012, 47, 195-207. [CrossRef] [PubMed]

18. Carrapiso, A.; García, C. Development in lipid analysis: Some new extraction techniques and in situ transesterification. Lipids 2000, 35, 1167-1177. [CrossRef] [PubMed]

19. Laurens, L.L.; Quinn, M.; Van Wychen, S.; Templeton, D.; Wolfrum, E. Accurate and reliable quantification of total microalgal fuel potential as fatty acid methyl esters by in situ transesterification. Anal. Bioanal. Chem. 2012, 403, 167-178. [CrossRef] [PubMed]

20. Palmquist, D.L.; Jenkins, T.C. Challenges with fats and fatty acid methods. J. Anim. Sci. 2003, 81, 3250-3254. [CrossRef] [PubMed]

21. Chen, C.-L.; Huang, C.-C.; Ho, K.-C.; Hsiao, P.-X.; Wu, M.-S.; Chang, J.-S. Biodiesel production from wet microalgae feedstock using sequential wet extraction/transesterification and direct transesterification processes. Bioresour. Technol. 2015, 194, 179-186. [CrossRef] [PubMed]

22. Rosenberg, J.N.; Kobayashi, N.; Barnes, A.; Noel, E.A.; Betenbaugh, M.J.; Oyler, G.A. Comparative analyses of three chlorella species in response to light and sugar reveal distinctive lipid accumulation patterns in the microalga c. Sorokiniana. PLoS ONE 2014, 9, e92460. [CrossRef] [PubMed]

23. Kwon, D.-Y.; Kwon, J.-H.; Jo, G.-J. Removal of algae and turbidity by floating-media and sand filtration. Desalin. Water Treat. 2013, 52, 1007-1013. [CrossRef]

24. Bligh, E.G.; Dyer, W.J. A rapid method for total lipid extraction and purification. Can. J. Biochem. Phys. 1959, 37, 911-917. [CrossRef] [PubMed]

25. Volkman, J.K.; Barrett, S.M.; Dunstan, G.A.; Jeffrey, S.W. C30-c32 alkyl diols and unsaturated alcohols in microalgae of the class eustigmatophyceae. Organ. Geochem. 1992, 18, 131-138. [CrossRef]

26. Shiu, P.-J.; Gunawan, S.; Hsieh, W.-H.; Kasim, N.S.; Ju, Y.-H. Biodiesel production from rice bran by a two-step in-situ process. Bioresour. Technol. 2010, 101, 984-989. [CrossRef] [PubMed]

27. Rosenberg, J.N.; Oyler, G.A.; Wilkinson, L.; Betenbaugh, M.J. A green light for engineered algae: Redirecting metabolism to fuel a biotechnology revolution. Curr. Opin. Biotechnol. 2008, 19, 430-436. [CrossRef] [PubMed]

28. Pieber, S.; Schober, S.; Mittelbach, M. Pressurized fluid extraction of polyunsaturated fatty acids from the microalga nannochloropsis oculata. Biomass Bioenergy 2012, 47, 474-482. [CrossRef]

29. Ryckebosch, E.; Bermúdez, S.; Termote-Verhalle, R.; Bruneel, C.; Muylaert, K.; Parra-Saldivar, R.; Foubert, I. Influence of extraction solvent system on the extractability of lipid components from the biomass of nannochloropsis gaditana. J. Appl. Phycol. 2014, 26, 1501-1510. [CrossRef]

30. Camacho-Rodríguez, J.; Cerón-García, M.C.; Fernández-Sevilla, J.M.; Molina-Grima, E. The influence of culture conditions on biomass and high value product generation by nannochloropsis gaditana in aquaculture. Algal Res. 2015, 11, 63-73. [CrossRef]

31. Chen, Y.; Vaidyanathan, S. Simultaneous assay of pigments, carbohydrates, proteins and lipids in microalgae. Anal. Chim. Acta 2013, 776, 31-40. [CrossRef] [PubMed]

32. Pulz, O.; Gross, W. Valuable products from biotechnology of microalgae. Appl. Microbiol. Biotechnol. 2004, 65, 635-648. [CrossRef] [PubMed]

33. Wen, Z.-Y.; Chen, F. Heterotrophic production of eicosapentaenoic acid by microalgae. Biotechnol. Adv. 2003, 21, 273-294. [CrossRef]

34. Adarme-Vega, T.C.; Thomas-Hall, S.R.; Schenk, P.M. Towards sustainable sources for omega-3 fatty acids production. Curr. Opin. Biotechnol. 2014, 26, 14-18. [CrossRef] [PubMed]

35. Mitra, M.; Patidar, S.K.; George, B.; Shah, F.; Mishra, S. A euryhaline nannochloropsis gaditana with potential for nutraceutical (epa) and biodiesel production. Algal Res. 2015, 8, 161-167. [CrossRef] 
36. Kim, C.W.; Sung, M.-G.; Nam, K.; Moon, M.; Kwon, J.-H.; Yang, J.-W. Effect of monochromatic illumination on lipid accumulation of nannochloropsis gaditana under continuous cultivation. Bioresour. Technol. 2014, 159, 30-35. [CrossRef] [PubMed]

37. Kobayashi, N.; Noel, E.; Barnes, A.; Rosenberg, J.; DiRusso, C.; Black, P.; Oyler, G. Rapid detection and quantification of triacylglycerol by hplc-elsd in chlamydomonas reinhardtii and chlorella strains. Lipids 2013, 48, 1035-1049. [CrossRef] [PubMed] 